\title{
Determinants of Sustainable Construction Practices in Ghana Using Structural Equation Modelling
}

\author{
Nongiba Alkanam Kheni ${ }^{1}$ \& Moses Ayaaba Akoogo ${ }^{2}$ \\ ${ }^{1}$ Faculty of Technical Education, University of Education, Winneba, Kumasi, Ghana \\ ${ }^{2}$ Zamse Senior High/Technical School, Bolgatanga, Ghana \\ Correspondence: Nongiba Alkanam Kheni, Department of Construction and Wood Technology Education, \\ College of Technology Education, University of Education, Winneba, P.O. Box 1277, Kumasi, Ghana. Tel: \\ 233-24-768-6774. E-mail: kalkanam@yahoo.com
}

Received: January 18, 2015 Accepted: January 26, 2015 Online Published: May 28, 2015

doi:10.5539/jsd.v8n3p67 URL: http://dx.doi.org/10.5539/jsd.v8n3p67

\begin{abstract}
Today's world is faced with a wide range of threats to the environment as well as the socioeconomic development. Construction industry has a role to play in ensuring a healthy-livable environment and equitable access to social infrastructure in developing countries. The purpose of the study is to examine the adoption of Sustainable Construction Practices (SCP) in the Ghanaian Construction Industry (GCI). The study adopted a quantitative research design involving structured questionnaire developed to collect data. Data was analyzed using descriptive statistics and Structural Equation Modeling (SEM) via Partial Least Squares (PLS). Two models were developed in the study: a direct model and an in direct model. The direct model findings suggest that four independent variables had a significant influence on adoption namely; compatibility (COM), knowledge (KNW), peer firm influence (PEER) and trialability (TRA) supported adoption while three independent variables namely; complexity(CPX), observability (OBS)and Relative advantage (RAV) did not. Based on the findings of the study, the study made recommendations which, if adopted, could lead to significant improvement in the adoption rate of SCP in Ghana.
\end{abstract}

Keywords: sustainable construction practice, intentions, adoption and structural equation modeling

\section{Introduction}

\subsection{Achieving Sustainable Construction Agenda in Ghana}

Ghana's development agenda remains a myth without construction works since construction is a major provider of infrastructure. Construction is also one of the ever growing industries in the world as it tries to meet the human needs in terms of housing, transport, communication, sanitation and water supply in addition to macroeconomic growth. Studies show that construction contributes between 5 and 10 percent of gross domestic product (GDP) in all countries, employs up to 10 percent of the working population, and is responsible for about half of the gross fixed capital formation (Ofori, 2012). Sadly, a significant number of the world's population lack access to basic social services such as drinking water, shelter and no reliable source of income. These factors underscore the need to explore measures to forestall the increasing rate of depletion of natural resources by the construction sector and through the sector, bridge the widening developmental gap between extremely deprived populations and those of higher social and economic status. Increasingly, there is growing awareness among many countries now than ever regarding the need to take measures to improve the performance of their construction industry (Ofori, 2001). Hence, many countries have tried in various ways to avoid the depletion of their non-renewable resources by embracing sustainable development.

The need for sustainable construction practices (SCP) has been noted by many scholars and practitioners in the construction literature (Kibert, 1994; Du Plessis, 2002; Chew, 2010; Häkkinen \& Belloni, 2011). Kibert (2007) says that healthy green buildings are springing up in many countries, which involve the use of new products and services while many research centers worldwide devote time and resources to investigate SC concepts, tools, technologies, materials, energy systems, water conservation, and many other connected matters. Most of these studies were done using qualitative methods to explore the opportunities, challenges, elements and perspectives on SCP in developing countries including Ghana (Du Plessis 2007; Ayarkwa, 2010; Kwakye, 2010). Clearly, 
there is the need to extend or augment these studies by examining the core factors that affect adoption of SC in the construction industry in Ghana using a quantitative approach. Identifying the factors that affect the adoption of SC will provide insight on firms' attitudes and behaviours in relation to SC and therefore serve as a foundation for designing interventions aimed at achieving sustainable construction goals at the firm level.

Construction firms' adoption of sustainable construction practices involves innovative strategies that will align developmental goals with sustainable construction principles. Considered from the perspective of innovation, sustainable construction will engender the introduction of new ideas, processes and technology transfer in construction firms to achieve the goals of sustainable construction. Apparently, the decision to adopt an innovation goes through a process and Rogers (2003) described this as the innovation-decision process and defines it as "an information-seeking and information-processing activity, where an individual is motivated to reduce uncertainty about the advantages and disadvantages of an innovation" (Rogers, 2003).

Rogers (2003) described the innovation-diffusion process as "an uncertainty reduction process" and he recommends features of innovations that will enhance the reduction of uncertainty about innovation. These features of innovation include: (1) relative advantage, (2) compatibility, (3) complexity, (4) trialability, and (5) observability. Rogers (2003) stated that "individuals' perceptions of these characteristics predict the rate of adoption of innovations." Rogers (2003) defined the rate of adoption as "the relative speed with which an innovation is adopted by members of a social system." This is measured by the number of adopters of that innovation per time. The perceived elements or attributes of an innovation are significant predictors of the rate of adoption.

\subsection{Significance of the Study}

Sustainable construction needs to be studied from the perspective firm practices. Factors that determine firms' behaviour in terms of what factors are important in the adoption of SC and how such factors will influence firms' intentions of adoption of SC will provide valuable insights on SC. Past studies have focused on finding the key enablers and challenges to adoption of SC in a more generalised context rather than at the construction firm level (Du Plessis 2007; Ayarkwa, 2010; Kwakye, 2010). The present study therefore seeks to fill this gap in knowledge. The findings of the study will assist construction firms to understand better and manage the SC process in Ghana and similar developing countries.

\subsection{Literature Review}

Agenda 21 for sustainable construction lays the foundation for determining sustainability in the construction industry. In the beginning, the interest was on the limitation of resources in terms of energy use and the reduction of construction impact on the natural environment. Later it shifted to technical issues like materials, building components, construction technology and energy related designs. Lately, issues of economic, social or cultural are given attention too.

Sustainability concentrated on how to reduce the negative impact on our natural environment. This initial concept of sustainability evolved over the years to include economic, social and cultural heritage. As Häkkinen \& Belloni, (2011) has put it "the impact of Sustainability could be categorized into three factors namely: Environmental: climate change, deterioration of ecosystem, use/depletion of resources. Economic: economic value, productivity. Social: health, satisfaction, equity, cultural value."Baloi (2003) also agree that sustainable construction embraces three main dimensions namely social, economic and environmental in contrast with the traditional perspective, where the main concerns were economy, utility, and durability. He explains that the social dimension addresses issues pertaining to the enhancement of people's quality of life. The economic dimension addresses economics issues such as employment creation, competitiveness enhancement, lower operating/maintenance costs, high quality of working environment leading to greater productivity and many others. The environmental dimension deals with the design, construction, operation or conservation and deconstruction approaches that reduce the adverse impacts on the environment such as air emissions, waste discharges, use of water resources, land use, and others. However, the preservation of cultural heritage as mention by others has been given due recognition by the author. The three major pillars of sustainable construction is further confirmed by Shimi (n.d) as categorized into:

- Social Dimension: explains that it is to create a built environment that meets people's needs no matter their circumstances, and provide affordable and healthy homes, and to enable them have access to services to enjoy a good quality of life. 
- Economic Dimension: this he said is to create high quality working environments that contribute to the development of healthy places of employment, increased productivity and competitiveness; that are adaptable to the changing needs of a vibrant economy.

- Environmental Dimension: Is to use materials and adopt forms of design and construction that use resources efficiently, minimize the generation of waste and pollution, protect and enhance biodiversity and create a healthy environment.

\subsection{Hypotheses}

Based on the original theory of reasoned action, a central factor in the theory of planned behaviour is the individual's intention to perform a given behaviour. Intentions are assumed to capture the motivational factors that influence a behaviour; they are indications of how hard people are willing to try, of how much of an effort they are planning to exert, in order to perform the behaviour. As a general rule, the stronger the intention to engage in behaviour, the more likely should be its performance. Based on the empirical and theoretical review of literature in sustainable construction practices globally and in Ghana, a conceptual framework is developed for the study (Figure 1). The conceptual framework for this study basically identifies the key constructs and variables that could help explain firms' adoption of SCP. It also justifies the hypothesized relationships among the variables or constructs (Table 1).

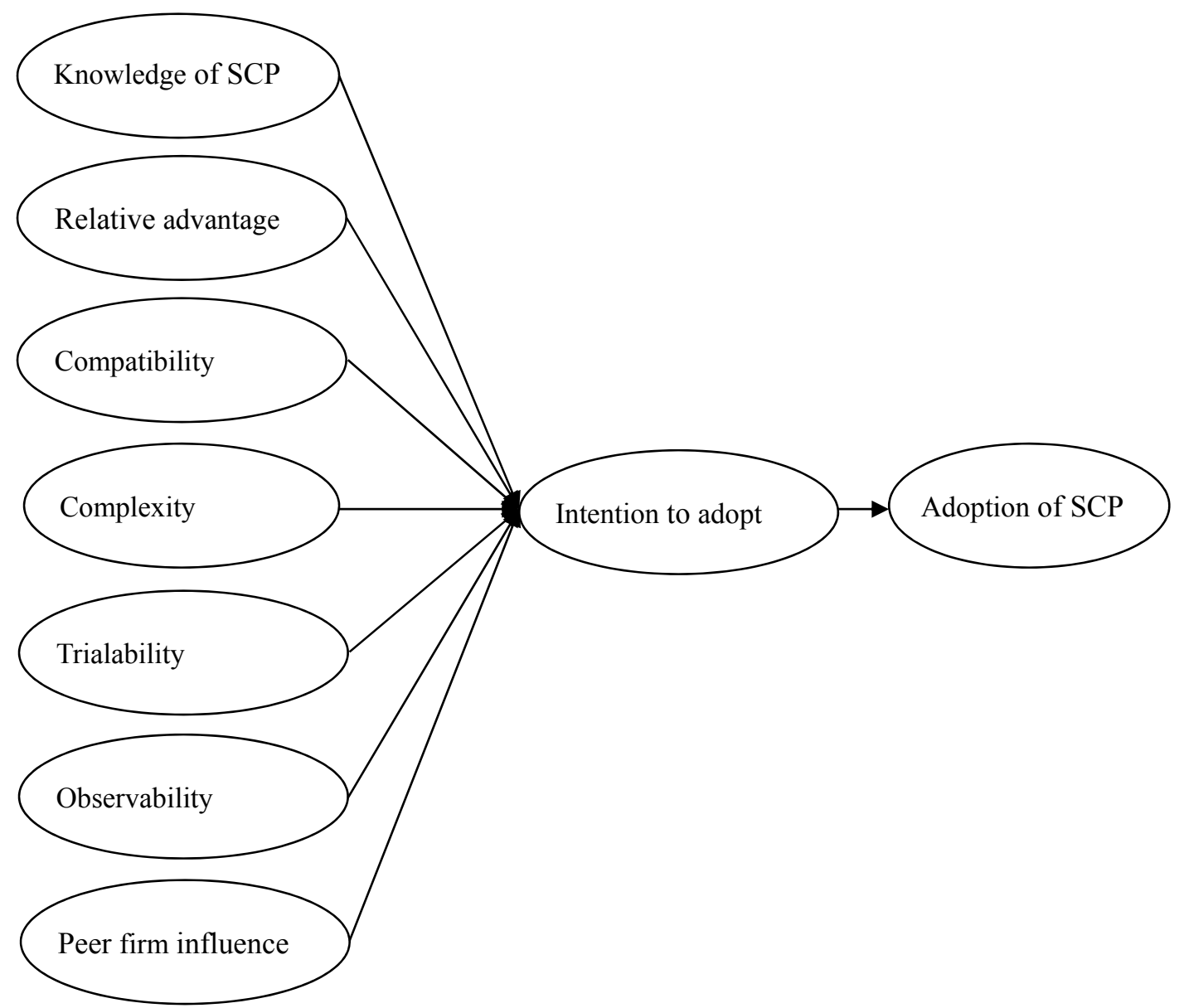

Figure 1. Conceptual framework and hypothesized relationships 
Table 1. Hypothesized statements

\begin{tabular}{|c|c|}
\hline Hypotheses & Statement \\
\hline H1: & Knowledge of SCP will have significantly positive effect on intention to adopt SCP. \\
\hline $\mathrm{H} 2$. & $\begin{array}{l}\text { Relative advantage of adopting SCP will have significantly positive effect on firms' } \\
\text { adoption of SCP. }\end{array}$ \\
\hline H3: & Compatibility will have a significantly positive influence in the adoption of SCP. \\
\hline H4: & Complexity of SCP will have significantly positive influence on intention to adopt SCP. \\
\hline H5: & Trialability of SCP will have significantly positive effect on intention to adopt SCP. \\
\hline H6: & Observability of SCP will have significantly positive effect on the intention to adopt SCP. \\
\hline $\mathrm{H} 7$ & Peer firm influence will have significantly positive effect on intention to adopt SCP. \\
\hline H8: & $\begin{array}{l}\text { The higher the intentions, the more likely a firm or an individual will develop a positive } \\
\text { behaviour towards adopting SCP. }\end{array}$ \\
\hline
\end{tabular}

\section{Methodology}

In this study, the main research design adopted is a quantitative approach involving survey questionnaires. The researchers employed a cross-sectional survey and a questionnaire as the instrument for gathering data. The choice was based on the fact that survey makes it possible for large amount of data to be derived from considerable population in a very efficient way (Hair, Black, Babin, Anderson, \&Tatham, 2010). Additionally, the approach is important in developing generalizations that contribute to theory (Creswell 1994:87-88). While primary data was mainly obtained through the use of questionnaire distribution, secondary data were collected through the following resources:

- Books and references.

- Periodicals, thesis and journals.

- Internet.

The study considered construction companies (contractors) belonging to two groups: The Association of Road Contractors of Ghana (ASROC) and the Association of Building and Civil Engineering Contractors of Ghana $(A B C E C G)$ in the ten regions of Ghana. Out of the ten regions, three regions were randomly selected as the target population of the study. The sampling frame for the research consisted of names of all registered contractors with the ABCECG and ASROC in the three selected regions

\subsection{Sampling}

Cooper \& Schindler (2006) noted that a minimum of five and maximum of twenty cases per parameter or the highest number of indicators for a construct can be adequate in assessing a structural model (Cooper \& Schindler, 2006). Therefore using these guidelines, for this study the highest number of indicators for a construct is three and the number of structural parameters is eight. By multiplying three or eight by 20 we get 60 and 160 respectively. Therefore, a sample size of 160 respondents was chosen for the present study. Assuming a non-response rate of 50 per cent, the actual sample size adopted for the study taking into consideration non-response is 240 .

\subsection{Questionnaire Development}

A draft questionnaire was developed and pretested in a setting similar to that in which data was to be collected. The final questionnaire developed comprised two sections; A and B. Section A requested for information on respondents' background and section $B$ required responses on questions that measured the constructs developed from the literature and contained in the conceptual framework. In the later section, respondents were requested to strongly disagree, disagree, remain neutral, agree or strongly agree on each item. These responses were coded 1-5 with1 representing Strongly Disagree, 2 representing disagree, 3 representing uncertain, 4 representing agree and 5 representing strongly agree. Direct administration of the questionnaire was done due to the advantages associated with it such as the likelihood of high response rate and timely completion of the questionnaires. Also, the procedure enabled the researchers to reduce cost and save time as they were available to provide assistance. These notwithstanding, there were related disadvantages of directly-administered questionnaires such as the restrictions posed on the researchers on where and when the questionnaire could be administered. 


\section{Analysis of Results}

\subsection{Response Rate and Characteristics of Respondents}

Out of two hundred and fifty (250) copies of the questionnaires that were printed and distributed, 178 were returned with eight of them not useable. 170 completed questionnaires were finally used for the analysis. This gave a response rate of 68 per cent. The strategies that contributed to the high response rate include; constant reminders sent to the respondents, personal visits to the respondents' work places and participation of the researchers in contractors' association meetings and talking with the executives of the associations.

A total of 164 respondents $(96 \%)$ were males while 6 respondents $(4 \%)$ were females. This is rather not surprising, given the fact that construction is widely regarded as a male preserve with rarely females taking up careers leading to construction professions (Dainty and Lingard 2006). The responses on age showed that 2 respondents $(1 \%)$ were below 20 years, 51 respondents $(30 \%)$ were $20-30$ years, majority of the respondents were within 31-40 recording 65 representing 38\%, 32 respondents (19\%) were 41-50 years and 20 respondents (12\%) were above 50 years. The response is a fair representation of the working population within the construction industry and an indication of the willingness of the youth to take up construction related professions. Respondents with different professional background within the construction industry responded to the survey. Seventeen of them (10\%) were architects, 45 respondents $(26 \%)$ were quantity surveyors, and structural engineers were 18 representing (11\%). The rest of the respondents (90) representing 53\% were of other professional background such as construction managers, geodetic engineers and construction tutors.Responses on number of years of practice showed that 52 respondents (31\%) had practiced below 5 years, 50 respondents (29\%) had 5-9 years of practice, and 30 respondents (17\%) had practiced for 15-19 years whiles 19 respondents representing $11 \%$ practiced for 20 years and above. The responses suggest that majority of the respondents had a wealth of experiences and that their responses to questionnaire items could be a fair reflection of the opinions of construction professionals in the field of sustainable construction practice.

\subsection{Factors Affecting Intentions to Adopt and Adoption of SCP in Ghana}

Structural equation model was used for the purpose of this study following the hypotheses developed based on the conceptual framework. The need to adopt some statistical tools to analyse the data such as SPSS 18.0 and Partial Least Squares (PLS) or Analysis of Moment Frameworks (AMOS) techniques became necessary, specifically, Smart PLS 2.0 (Ringle, Wende, \& Will, 2005) was used for the analysis of the resulting data.SPSS was used for data entry and screening while the PLS was used to test the hypothesized relationships among constructs or variables in the model proposed in the conceptual framework. PLS path modeling was chosen over AMOS because of its non-distributional assumptions, its ability to take single item variables, and its predictive power. The field data collected shows that the data set is non-normal and the focus of the study was on factors that can help to explain or predict the adoption of SCP among construction professionals in Ghana.

PLS model analysis follows a two-step approach, outer model (the measurement model) and the inner model (structural) assessment. First, construct reliability and validity are assessed for the measurement model, and then the regression weights and predictive validity of the inner (structural) model or relationships are assessed. For the purpose of simplicity of analysis, the following codes were used for the constructs throughout the analysis: knowledge (KNW) compatibility (COM), relative advantage (RAV), peer firm influence (PEER), complexity (CPX) also referred to as perceived difficulty, observability (OBS), trialability (TRA) and intention (INT). Two structural models were estimated, one for the indirect model where intention to adopt predicts actual adoption of SCP, and a direct model where all the adoption determinants are modeled to predict actual adoption of SCP.

\subsubsection{Assessment of Structural Model (Indirect Model)}

In PLS path modeling, the structural model is assessed through the R-square for predictive power and significance of $\mathrm{t}$-values for regression weights at a chosen significant value of 0.05 level; equally $\mathrm{t}$-values that are equal to or greater than 1.96 will be judged significant (Chin, 2010; Hair, Ringle \&Sarstedt, 2011, Hulland, 1999). For the indirect model, the regression weights of the hypothesized relationship and predictive power of model (R-square) are presented in Table 2 and Figure 2. 
Table 2. Indirect model assessment: regression weights and predictive power

\begin{tabular}{llllll}
\hline Hypothesis & Hypothesized & Regression & & & \\
\hline H5 & Relationship & Weight $(\beta)$ & t-value & p-value & Remarks \\
H6 & TRA -> INT & 0.335 & 4.155 & 0.000 & Supported \\
H8 & OBSV -> INT & 0.283 & 4.377 & 0.000 & Supported \\
H2 & INT -> SCP & 0.218 & 3.151 & 0.002 & Supported \\
H3 & RAV -> INT & 0.161 & 2.306 & 0.022 & Supported \\
H7 & COM -> INT & 0.097 & 1.282 & 0.201 & Not Supported \\
H4 & PEER -> INT & 0.072 & 1.122 & 0.263 & Not Supported \\
H1 & CPX -> INT & 0.051 & 0.730 & 0.466 & Not Supported \\
R square & KNW -> INT & 0.024 & 0.391 & 0.696 & Not Supported \\
\hline
\end{tabular}

Notes: knowledge (KNW), Compatibility (COM), Relative advantage (RAV), Peer firm influence (PEER), Complexity or difficulty (CPX), Trialability (TRA), and Intentions (INT)

Table 2.Shows the results of the hypothesis testing for the proposed research model. It indicates that, for the indirect relationships implied in hypotheses $\mathrm{H} 1$ to $\mathrm{H} 8$, four of them were supported by the data. Specifically, TRA significantly influences INT by $33.5 \%(\beta=0.335, \mathrm{t}=4.155, \mathrm{p}<0.05)$ confirming hypothesis H5. OBS significantly influences INT by $28.3 \%(\beta=0.283, \mathrm{t}=4.377, \mathrm{p}<0.05)$, supporting hypothesis H6. INT significantly influences SCP by $21.8 \%(\beta=0.218, \mathrm{t}=3.151, \mathrm{p}<0.05)$, supporting hypothesis H8. Lastly, RAV significantly influences INT by $16.1 \%(\beta=0.161, \mathrm{t}=2.306, \mathrm{p}<0.05)$, providing support for hypothesis $\mathrm{H} 2$. However, H1, H3, H4, and H7 were not supported. Specifically, KNW did not significantly influence INT ( $\beta=$ $0.024, \mathrm{t}=0.391, \mathrm{p}=0.05$ ), disproving hypothesis $\mathrm{H} 1$. COM influenced INT by $9.7 \%$ but this was not significant $(\beta$ $=0.097, \mathrm{t}=1.282, \mathrm{p}=0.05$ ), providing evidence to reject hypothesis H3. Lastly PEER also did not significantly influence INT $(\beta=0.072, t=1.122, p=0.263)$ thereby disproving hypothesis $\mathrm{H} 7$.

The predictive power of the model is assessed through the R-square statistic. Together, the proposed model explains $42 \%\left(\mathrm{R}^{2}=0.42\right)$ of intention to adopt SCP and $5 \%$ of actual adoption of SCP $\left(\mathrm{R}^{2}=0.05\right)$. This means that the independent variables, knowledge (KNW), Compatibility (COM), Relative advantage (RAV), Peer firm influence (PEER), Complexity or difficulty (CPX), Trialability (TRA), and Intention (INT), together explain the outcome of the predictive result of the model. 


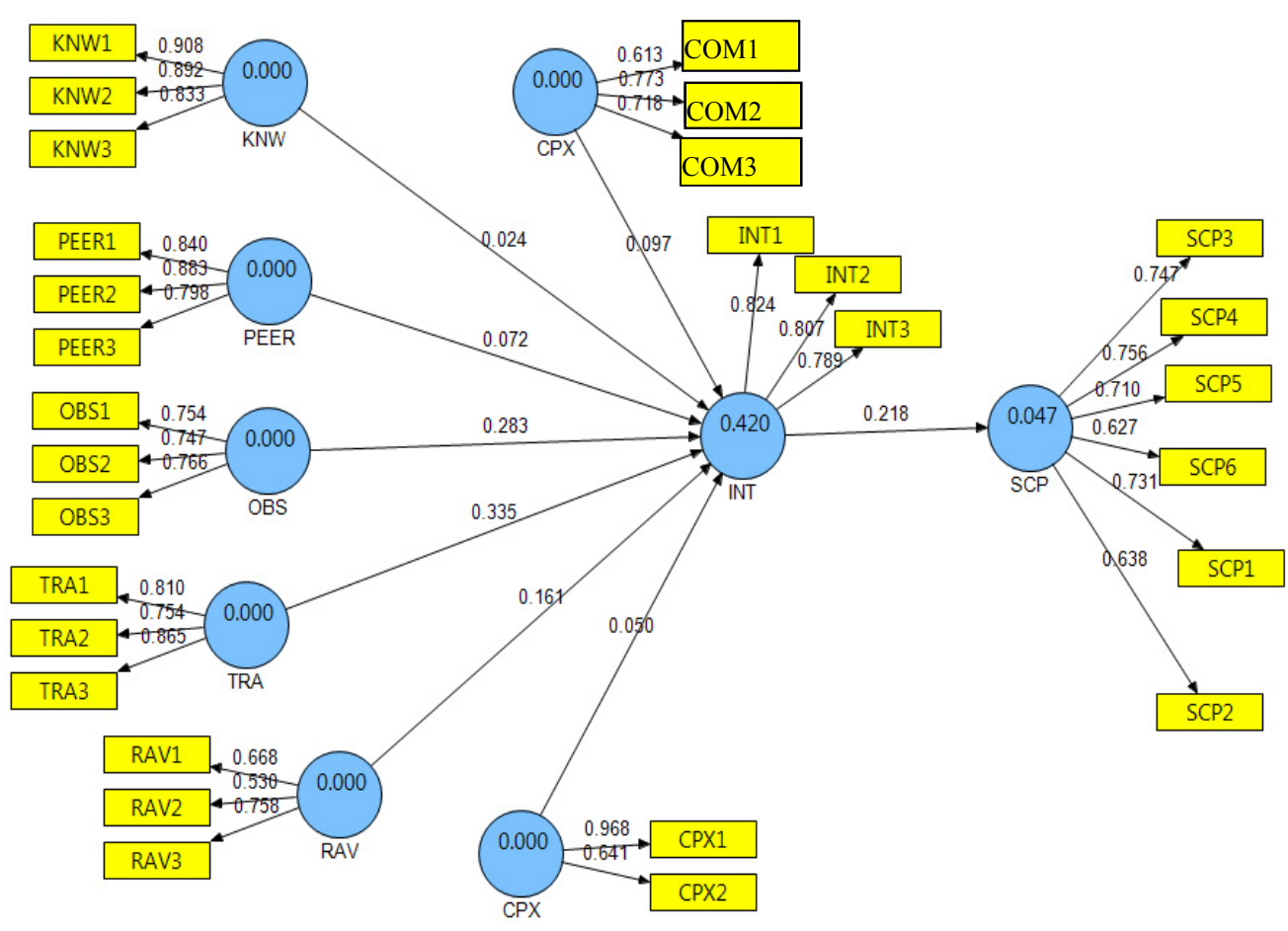

Figure 2. Assessment of hypothesized relationships and predictive power of the indirect model

\subsubsection{Assessment of Structural Model (Direct model)}

For the direct model, the regression weights of the hypothesized relationship and predictive power of model (R-square) are presented in Table 3 and Figure 3.

Table 3. Direct model assessment: weights and predictive power

\begin{tabular}{llllll}
\hline S/N & $\begin{array}{l}\text { Hypothesized } \\
\text { Relationship }\end{array}$ & $\begin{array}{l}\text { Regression } \\
\text { Weight }(\beta)\end{array}$ & T-value & P-value & Remarks \\
\hline 3 & KNW -> SCP & 0.260 & 3.151 & 0.002 & Supported \\
1 & COM -> SCP & 0.177 & 2.271 & 0.024 & Supported \\
5 & PEER - > SCP & 0.193 & 2.438 & 0.016 & Supported \\
7 & TRA - > SCP & 0.126 & 1.982 & 0.022 & Supported \\
4 & OBS -> SCP & 0.031 & 0.393 & 0.695 & Not Supported \\
2 & CPX -> SCP & 0.012 & 0.161 & 0.873 & Not Supported \\
6 & RAV -> SCP & -0.005 & 0.050 & 0.961 & Not Supported \\
R square & 0.27 & & & & \\
\hline
\end{tabular}

Note: knowledge (KNW), Compatibility (COM), Relative advantage (RAV), Peer firm influence (PEER), Complexity or difficulty (CPX), Trialability (TRA), Intention (INT), and Observability (OBS).

Table 3 shows the results of the hypothesis testing for the proposed research model. It indicates that, for the direct relationships implied in serial numbers $\mathrm{H} 1$ to $\mathrm{H} 8$, four of them were supported. Specifically, COM significantly influences SCP by $17.7 \%(\beta=0.177, \mathrm{t}=2.271, \mathrm{p}<0.05)$. KNW significantly influences SCP by $26.0 \%(\beta=0.260, \mathrm{t}=3.151, \mathrm{p}<0.05)$, PEER significantly influences SCP by $19.3 \%(\beta=0.193, \mathrm{t}=2.438, \mathrm{p}<$ $0.05)$, TRA also influence SCP by $12.6 \%(\beta=0.126, \mathrm{t}=1.782 \mathrm{p}<0.321)$. However, H2, H4 and H6 were not supported. This is proven by the results of the table as in table 4.6 above. CPX did not influence SCP because $\beta$ 
$=0.012, \mathrm{t}=0.161$, and $\mathrm{p}=0.873$, OBS also failed to influence $\mathrm{SCP}$ as $\beta=0.031, \mathrm{t}=0.393$, and $\mathrm{p}=0.695$. That of RAV had $\beta=0.005, t=0.050, p=0.961$ hence failing to influence SCP directly.

The predictive power is assessed through the R-square statistics. Together, the proposed model explains $27 \%\left(\mathrm{R}^{2}\right.$ $=0.27$ ) of adoption of SCP without intention as an intervening variable. This means the independent variables: knowledge (KNW), Compatibility (COM), Relative advantage (RAV), Peer firm influence (PEER), Complexity or difficulty (CPX), Trialability (TRA), together explain that it is possible to adopt SCP without first developing an intention (INT). It therefore, suggests that the direct model in Figure 3 comparatively has a greater influence on adoption without the intervening variable (INT) since the predictive power of the direct model is $27 \%$ ( $\mathrm{R}^{2}$ $=0.27$ ), which is greater than that of the indirect model (see Figure 1), predicting $5 \%\left(\mathrm{R}^{2}=0.05\right)$ of actual adoption of SCP. The direct model assessment diagram below displays the generated structural regression weights of the measurement items, constructs and the predictive power of the direct model $\left(\mathrm{R}^{2}\right)$.

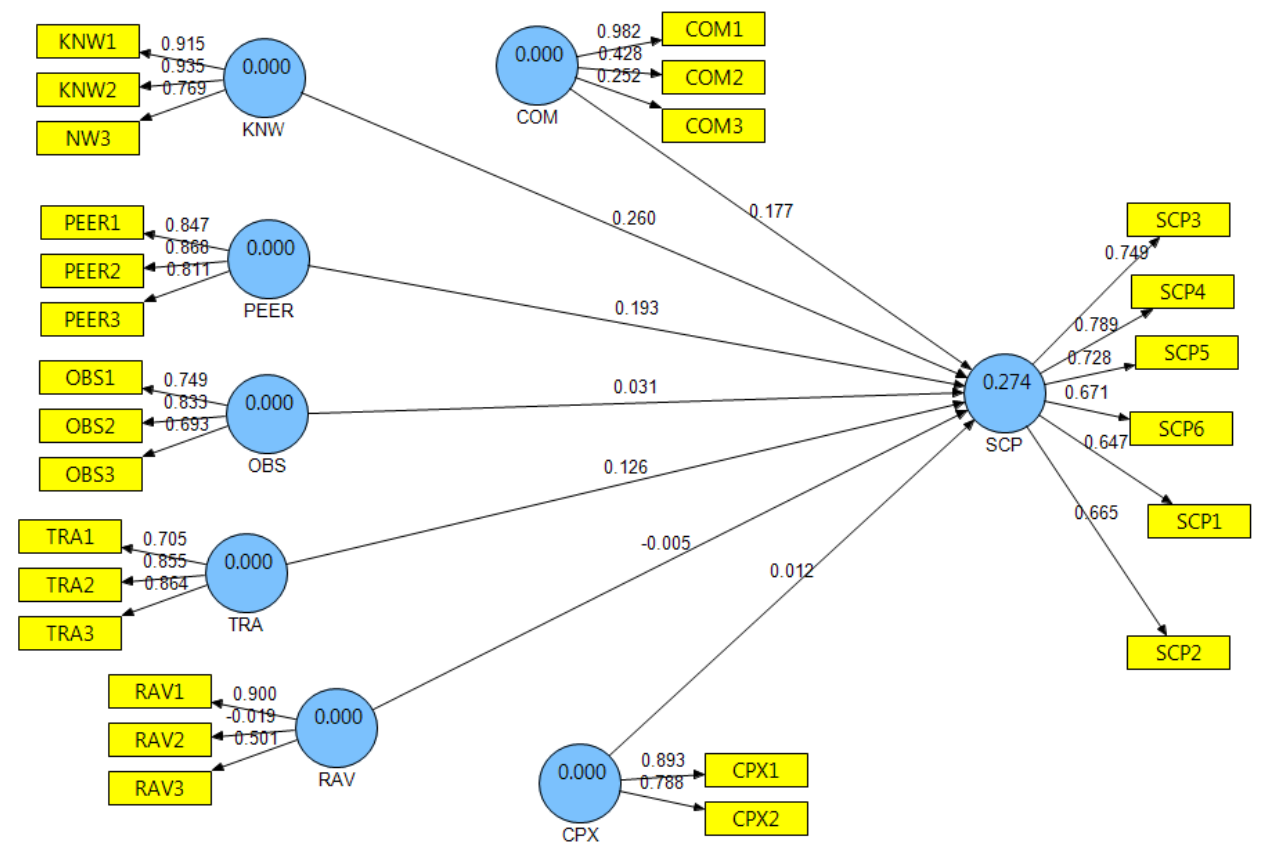

Figure 3. Direct model assessment: weights and predictive power

\section{Discussion}

\subsection{Models}

The research generated two models to test the factors that could affect adoption of SCP in Ghana. The models generated were the direct and indirect models. The indirect model consists of factors and their influence on the intentions to adopt based on Rogers theory of adoption. The second model considered factors that have direct effect on adoption without intention. The two models are discussed in the sections that follow.

\subsubsection{The Indirect Model}

This model as shown in Figure 4 considers the significant influence of the independent variables on intention to adopt and their regression weight on intention, it also show the predictive power of the model on adoption. 


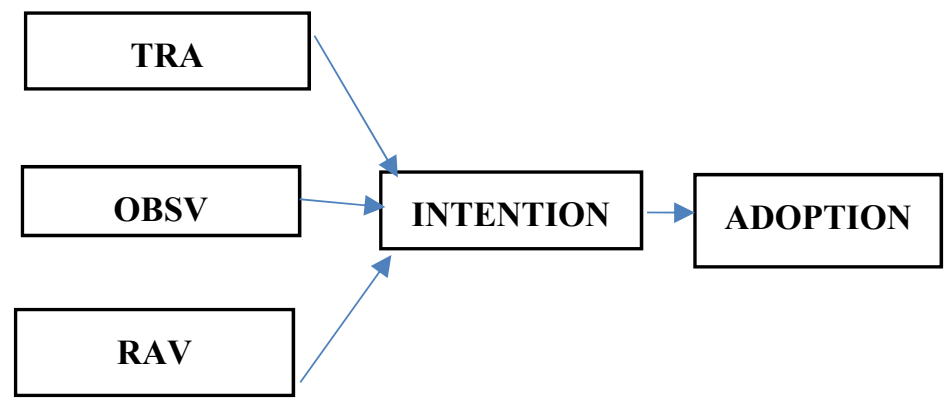

Figure 4. The indirect structural model of adoption

Eight hypothesized relationships were established to answer the research question. Out of the eight, four of the hypotheses were supported by the results of the research to have significantly influence intention to adopt. The results confirmed Rogers (2003) theory of intention having influence on adoption. This suggests that factors such as RAV, TRA and OBS will have influence on people's intention to adopt a certain style or change. It is also proven that when there is an intention, then the possibility to adopt is high (Rogers, 2003). We can deduce from the results that for any significant improvement to be made in adopting SCP in Ghana, then relative advantage of SCP should be heightened for construction professionals, contractors and clients to develop more intentions to adopt. Moreover, as explained by Rogers 2003, where the advantages of SCP are explained with its attendant benefits in the short and long term relative to traditional methods of construction, many are likely to adopt once a positive intention is developed towards the advantages of SCP over traditional methods of construction.

The second construct or independent variable that significantly influenced intention was trialability (TRA). This is a state were individuals begin to experiment with a new innovation. Trying is the beginning of practice and when the trail becomes a success it turns into motivation to continue. SCP could be adopted in Ghana when people are willing to try it as it influences their intention to adopt apparently confirming the hypothesis on TRA.

The third factor that had a significant influence on intention was observability (OBS). The ability to observe innovation gives credence to intention due to the influence observation has over intention. A well observed project could as well be duplicated in other areas. And once clients can identify and differentiate between the beauty and benefits of SCP and traditional methods of constructed works, the better the intention to adopt. The data results on observability supported the hypothesis. On the other hand, this may as well explain that when construction professionals as well as clients cannot observe the differences, their interest and intention to adopt SCP may not be effective. Thus it could explain the current state of adoption of SCP in Ghana since the practice is not popular.

Intention significantly influenced adoption of SCP as hypothesized is already an established theory been supported by the data as it is. The more the intention the more likely adoption could take place (Roger, 2003). The indirect model showed that intention has significant influence on adoption with a regression weight of $22 \%$ and $5 \%$ predictive power. The other independent variables such as knowledge, (KNW), compatibility (COMP), complexity (CPX) did not have any significant influence on intention to adopt SCP. It is most likely that peoples' knowledge lead them to practice than developing an intention to do it as the regression weight is only $2.4 \%$. Knowledge may not influence intention but adoption. The hypothesized relationship was not supported by the data.

Compatibility could be relevant or significant in other areas including adoption but not on intention to adopt SCP.Most likely because compatibility is seen as the degree to which an innovation is perceived as consistent with the existing values, past experiences, and needs of potential adopters (Rogers, 2003), the practice of SCP is not that common in Ghana and the difficulty to equate its consistency values with existing buildings. This might have influenced the outcome of the results of the data on intentions. Considering Roger's (2003) definition of complexity as "the degree to which an innovation is perceived as relatively difficult to understand and use", it is plausible that complex things may scare adopters away as it easily gives room for attempting contractors to abandon intention due to frustration and likelihood of quitting. Apparently, complexity was rated as a challenge though the least in the adoption of SCP and not an influential factor to adopt. A perceived difficulty could mislead or erode any intention. But we cannot rule out the fact that where a complex innovation makes the work easier, it could also influence firms to adopt. As said earlier the practice could be effectively applicable in other 
areas but complexity in SCP yields little influence in intention to adopt and therefore failed to support the hypothesis of having positive influence to adopt.

Peer firm influence is as result of subjective norms which represent the influence of the norms of important people to an individual, which includes social groups such as peers, family and co-workers among others (Ajzen\&Fishbein, 1980). The practice of SCP by other firms may not influence intention by other firms to adopt. The reason could be that the type of construction is determined by the clients' demand which lead to the kind of design before construction. Contractors are to execute the demand of clients and most likely the reason why the result did not support the hypothesis.

\subsubsection{The Direct Model.}

The second structural model developed was the direct model which examined the direct influence of the factors of adoption to adoption without the intervening variable (intention). Though there were no hypotheses to these effects, the data analysis suggest significant influence in adoption without the intervening variable (intention) to adopt. Four out of seven independent variables had a significant influence on adoption. Compatibility (COM), knowledge (KNW), peer firm influence (PEER) and trialability (TRA) supported adoption (Figure 5).

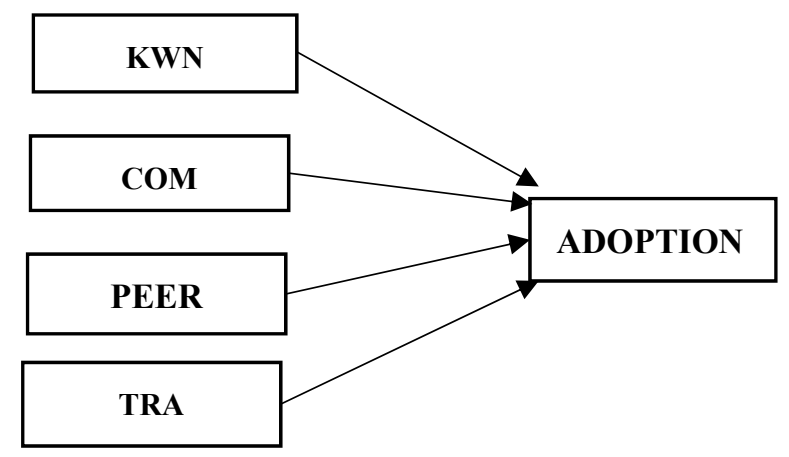

Figure 5. The direct structural model of adoption

Compatibility had a strong influence with a regression weight value of $17 \%$ supporting adoption. Though it did not support intention to adopt, it rather influenced adoption directly. The result could be an indication that where some firms adopt SCP, other firms may try to adopt because what seems new and attractive will certainly attract some imitation. Here knowledge (KNW) had a significant influence in adopting SCP in Ghana. This though wasn't the case of the indirect model, this results here could mean the contractors are likely going to adopt SCP so long as they have sufficient knowledge about it. This knowledge could come through training, workshops, and seminars on practices and benefits of SCP (Ross, et al, 2010). The findings also brings to bear the importance knowledge play in the adoption of SCP. This finding is in accord with Kwakye's (2010) findings and the responses to the challenges on SCP where lack of knowledge came second as a challenge to adopting SCP.

Peer firm influence also had an influence in the adoption of SCP base on the fact that the practice that will lead to cost reduction, less time spending, and improvement in performance will call for trail by some companies. Gerlach (2003) described it as sufficiency, efficiency, consistency strategies. Trialability as defined by Rogers (2003) is the degree to which an innovation may be experimented with on a limited basis." Trialability had proven to support or has an influence on adoption and not intention as proven in the indirect model. The possible reasons to explain this phenomenon could be, while architects, engineers, contractors and clients are willing to try SCP, generally they will adopt it either in the process of trying or at the end of the trail. But the earlier the trial the more likely is the adoption. This is explained by Rogers (2003) that earlier adopters experience the trialability attributes than late adopters.

The findings on the effect of the models developed to test the adoption of SCP showed; the direct model had a significant influence and for that matter it is recommended for effective adoption than the indirect model which had a modest influence on intention to adopt. If long term measures must be considered for adoption, then it is prudent to recommend the indirect model to strengthen intention among practitioners and gradually leading to adoption. Also, further work needs to be done using other workers within the construction sector to determine the effectiveness of the generated models. 


\section{References}

Ajzen, I., \& Fishbein, M. (1980). Understanding attitudes and predicting social behaviour. Englewood Cliffs, NJ: Prentice Hall.

Ayarkwa, J. (2010). Perspectives on environmental management in the construction industry in Ghana. International Journal on sustainable development, 60-68.

Baloi, D. (2003). Sustainable construc tion: challenges and opportunities. In D. J. Greenwood (Ed.), 19th Annual ARCOM Conference (pp. 289-297). University of Brighton.: Association of Researchers in Construction Management.

Bourdeau, L. (1999). Agenda 21 on sustainable construction. Rotterdam: CIB report Publication 237.

Chew, K. C. (2010). Singapore's strategies towards sustainable construction: The IES Journal Part A: Civil \& Structural Engineering, 3:3, 196-202. http://dx.doi.org/10.1080/19373260.2010.491641

Chin, W. W. (2010). Bootstrap cross-validation indices for PLS path model assessment. In V. Esposito Vinzi, W. W. Chin, J. Henseler, \& H. Wang (Eds.), Handbook of partial least squares: Concepts, methods and applications (pp. 83-97). Berlin, Germany: Springer-Verlag. http://dx.doi.org/10.1007/978-3-540-32827-8_4

Cooper D, R.,\& Schindler, P. S. (2006). Business Research Methods(9th ed.). New York Ny, McGraw Hill/Irwin.

Creswell, J. W. (1994). Research Design, Qualitative and Quantitative Approaches. Sage Publications, Inc., Thousand Oaks.

Dainty, A.R.J., \& Lingard, H. (2006). Indirect discrimination in construction organisations and the impact on women's careers. Journal of Management in Engineering, 22(3), 108-118. http://dx.doi.org/10.1061/(ASCE)0742-597X(2006)22:3(108)

Djokoto, S. D., Dadzie, J., \&Ababio, E. (2014). Barriers to Sustainable Construction in the Ghanaian Construction Industry: Consultants Perspectives . Journal of Sustainable Development, 7(1), 134-143. http://dx.doi.org/10.5539/jsd.v7n1p134

Du Plessis, C. (2007). A strategic framework for sustainable construction in developing countries. Construction Management and Economics, 25(1), 67-76. http://dx.doi.org/10.1080/01446190600601313

Du Plessis, C. (2002). Agenda 21 for sustainable construction in developing countries. Pretoria,: CSIR Building and Construction Technology.

Hair, J.F.Jr., Black, W.C., Babin, B.J., Anderson, R.E., \& Tatham, R. L. (2010). Multivariate data analysis. Upper Saddle, NJ: Pearson Prentice Hall.

Hair, J. F., Jr., Ringle, C. M., \& Sarstedt, M. (2011). The use of partial least squares (PLS) to address marketing management topics. Journal of Marketing Theory and Practice, 19(2), 135-252.

Häkkinen,\& Belloni. (2011). Barriers and drivers for sustainable building,. Building Research \& Information, 239-255. http://dx.doi.org/10.1080/09613218.2011.561948

Hulland, J. (1999). Use of partial least squares (PLS) in strategic management research: A review of four recent $\begin{array}{lllll}\text { studies. Strategic } & \text { Management }\end{array}$ http://dx.doi.org/10.1002/(SICI)1097-0266(199902)20:2<195::AID-SMJ13>3.0.CO;2-7

Kwakye, E. (2010). Barriers and opportunities to the adoption and implementation of sustainable construction techniques and practices in Ghana. MSc dissertation.Portsmouth: University of Portsmouth.

Kheni, N. A. (2008). Impact of health and safety management on safety performance of small and medium-sized construction businesses in ghana.Loughborough: Creative Common.

Kibert, C.J. (2007). Sustainable Construction - Green Building Design and Delivery. John Wiley \& Sons.

Kibert, C. J. (1994). Establishing Principles and a Model for Sustainable Construction. proceeding, First International Conference on Sustainable Construction (pp. 1-9). Tampa, Floirda.

Ministry of Water Resources, Works \& Housing. (2013). Ministry of Water Resources, Works \& Housing. Accra: Government of Ghana Official Portal.

Ofori, G. (2001). Indicators for Measuring Construction Industry Development In Developing Countries. Building Research \& Information, 40-50. http://dx.doi.org/10.1080/09613210150208787 
Ofori, G. (2012). Developing the Construction Industry in Ghana: the case for a central agency. Singare: National University of Singapore.

Ringle, C.M., Wende, S., \& Will, A. (2005). Customer segmentation with FIMIX-PLS.In Aluja et al. (Eds.),Proceedings of the PLS'05 International Symposium.Barcelona.

Rogers, E. M. (2003). Diffusion of innovations (5th ed.). New York: New York: Free Press.

Shimi, C. J. (n.d). Dundee sustainable development guide for construction. Dundee: Sustainable Construction Working Group of Dundee City Council.

\section{Copyrights}

Copyright for this article is retained by the author(s), with first publication rights granted to the journal.

This is an open-access article distributed under the terms and conditions of the Creative Commons Attribution license (http://creativecommons.org/licenses/by/3.0/). 